\title{
XXIV. Sequel to an essay on the constitution of the atmosphere, published in the philosophical transactions for 1826; with some account of the sulphurets of lime
}

\author{
John Dalton D.C.L. F.R.S.
}

To cite this article: John Dalton D.C.L. F.R.S. (1838) XXIV. Sequel to an essay on the constitution of the atmosphere, published in the philosophical transactions for 1826; with some account of the sulphurets of lime , Philosophical Magazine Series 3, 12:73, 158-168, DOI: $10.1080 / 14786443808649400$

To link to this article: http://dx.doi.org/10.1080/14786443808649400

$$
\text { 曲 Published online: } 01 \text { Jun } 2009 .
$$

Submit your article to this journal ¿

\section{山 Article views: 3}

Q View related articles ¿ 


\section{$\left[\begin{array}{ll}158\end{array}\right]$}

XXIV. Sequel to an Essay on the Constitution of the Atmosphere, published in the Philosophical Transactions for 1826; with some Account of the Sulphurets of Lime. By John DaLton, D.C.L., F.R.S. \&.**

T $\mathrm{N}$ an essay of mine on the constitution of the atmosphere, which was printed in the Transactions for 1826, I signified my intention of following it with a sequel of experiments to ascertain if possible which of the two views therein developed was most countenanced by facts. I now proceed to give an account of such investigations relating to this subject as have engaged my attention during a long period of years.

It may be needful to premise certain facts which are, I believe, universally admitted as indisputable; namely, that the atmosphere consists principally of two elastic fluids, azote and oxygen, either mixed by some mechanical law, or otherwise combined by a chemical principle in proportion nearly as four parts of the former to one of the latter in volume; that the two elastic fluids may be obtained separately in a state of purity; that when thus obtained they may be mixed in all possible proportions; and that the aggregate volumes in such cases are just equal to the sum of the two volumes of the ingredients; also, that any body which has a chemical affinity for either of them, so as to combine with it in a separate state, will also combine with it in the mixed state.

It is also pretty generally admitted that oxygen and azote are capable of chemical combinations in five or more definite proportions, namely,

2 vol. of azote with 1 vol. of oxygen-forming 2 vol. of nitrous oxide.

1 vol. of azote with 1 vol. of oxygen-forming 2 vol. of nitrous gas.

1 vol. of azote with $1 \frac{1}{2}$ vol. of oxygen-forming $1 \frac{1}{2}$ vol. of hyponitrous acid.

1 vol. of azote with 2 vol. of oxygen-forming 2 vol. of nitrous acid vapour.

1 vol. of azote with $2 \frac{1}{2} \mathrm{vol}$ of oxygen-forming $2 \frac{1}{2}$ vol. of nitric acid.

There does not appear to be a doubt of the reality of five combinations, but all chemists are not agreed as to the proportions of the volumes being precisely as above specified, chiefly because no general law has been found to obtain in such gaseous compounds.

These compounds are never formed nor decomposed without manifest chemical agency; they all contain oxygen, but

- From the Philosophical Transactions, 1837, Part ii. = an abstract of Dr. Dalton's former paper will be found in Phil. Mag., First Series, vol. lxvii., p. 310. 
no portion of it can be abstracted from any one of them without some chemical operation; whereas nitrous gas will immediately seize the oxygen from any of the afore-mentioned mixtures, the same as if it was alone, whatever may be the proportions. Atmospheric air itself, or any artificial mixture of the two gases in the same proportion as common air, is equally affected by nitrous gas and by every other agent.

Waving at present any consideration as to the nature and properties of the above chemical compounds, I shall now proceed to state the means by which the proportions of oxygen and azote in mixtures of these two gases may best be determined. Having been engaged in this investigation occasionally for more than forty years, I may be entitled to give my opinion on this important subject in practical chemistry.

Various methods of analysing common air have been discovered in the last fifty years. I have principally directed my attention to three, namely, (1.) by the use of Volta's eudiometer and hydrogen, or (2.) by nitrous gas, or (3.) by quadrisulphuret of lime, to abstract the oxygen from the azote.

\section{First Method, by Volta's Eudiometer.}

Mr. Cavendish was one of the first to investigate the changes produced by firing mixtures of hydrogen and common airs in various proportions. (Vid. Philos. Trans. 1784.) The following table will exhibit a lasting monument of his skill in effecting such an investigation. Many have attempted since to improve the methods of analysis, and have brought out results widely differing from those to be derived from his table; but it is now universally allowed that his results are nearer approximations to the truth than most of those we have seen since.

His method was to take 100 measures of common air and mix them with various proportions of hydrogen, beginning with upwards of 100, and gradually descending till about 20; then, firing each mixture by an electric spark, he marked the diminution of the mixture each time as under.

The following results are extracted from Mr. Cavendish's Table, except the last column, "Amendment," which I have attached, for reasons assigned below.

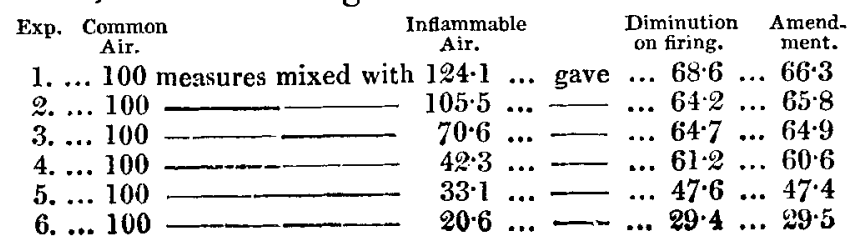




\section{Dr. Dalton on the Constitution of the Atmosphere,}

In the first three experiments no oxygen was found in the residuary gas; in the fourth a trace of oxygen was found; and in the fifth and sixth, considerable quantities of oxygen were found in the residues.

It is obvious that Mr. Cavendish began intentionally with an overdose of hydrogen, probably expecting the diminution to be a constant quantity till the hydrogen became deficient, and then of course the diminution must be lessened; this was not the case exactly; but the reason is easily discovered, and it proves the accuracy of the observations.

Hydrogen gas is rarely obtained quite pure: it frequently holds two or three per cent. of common air, detached from the water through which it bubbles and by other means; this air increases as more water enters the hydrogen bottle, till sometimes it amounts to ten per cent. at the last, as every one knows who has had a due share of experience. Now as Mr. Cavendish does not mention the purity of his hydrogen, we must try it by the means now generally known, as the reported results will guide us in the investigation.

On looking at the column headed "diminution on firing" it is easy to see there is a discrepancy in the first three experiments in that column; if the hydrogen used contained any oxygen the diminution on firing ought to have continually decreased, wherens it was greater in the third than in the second experiment. This it must be allowed is a proof of inaccuracy in one or both of the experiments; but it is no greater error than usually occurs if we trust to a single experiment with any gaseous mixture. The average of two or three experiments on mixtures of the same proportions should be taken. The fourth experiment clearly shows that the hydrogen contained oxygen as well as azote; for a diminution of 61.2 would denote the union of 20.4 oxygen with 40.8 hydrogen; hence there must have been 1.5 common air in the hydrogen. I have formed the column "amendment" by assuming the hydrogen in all the experiments to contain $4 \frac{1}{2}$ per cent. common air. If we combine the results of the third and fourth experiments, either by assuming Mr. Cavendish's diminution or that of the amendment, we shall obtain a very good approximation to the quantity of oxygen in atmospheric air, the former experiment giving too great diminution by reason of the excess of hydrogen and that containing some oxygen, and the latter giving too little diminution for want of the requisite quantity of hydrogen; the former will give 20.98 per cent. oxygen, and the latter 20.92 per cent. oxygen in atmospheric air. If any doubt should remain as to $\mathrm{Mr}$. Cavendish's hydrogen containing oxygen, it is removed by 
the consideration that his first experiment would indicate 22.9 oxygen per cent. in air, which cannot be allowed; and his last experiment that $8 \cdot 8$ oxygen must have combined with $20^{\circ} 6$ hydrogen instead of $17 \cdot 6$, which is equally inadmissible.

Since the period 1784, it has been found by various chemists that in mixtures of oxygen and hydrogen, as well as in other similar ones, the electric spark does not always cause an explosion, and when it does a complete combination does not always take place, but that in the residue sometimes portions of both the ingredients may be found. The limitations and restrictions are now pretty generally known; and with regard to the mixtures of cornmon air and hydrogen, I published a letter in the 10th volume of the Annals of Philosophy, (New Series) page 304, in which I showed the limitations found by my own experience to be as under:

Common air and hydrogen in which the oxygen is only $\frac{1}{13}$ th, or from six to seven per cent. of the whole mixture, do not explode.

Common air and hydrogen in which the oxygen is only $\frac{1}{14}$ th, or seven per cent. explode imperfectly, leaving both oxygen and hydrogen.

Common air and hydrogen in which the oxygen is from $\frac{1}{13}$ th to $\frac{1}{6} \cdot \frac{1}{86}$ th, or from eight to fourteen or fifteen per cent., fire leaving hydrogen and azote only.

Common air and hydrogen in which the hydrogen is $3.5 \overline{8}^{\text {th }}$ to $\frac{1}{7}$ th, or from fourteen to thirty per cent., fire and leave oxygen and azote only.

Common air and hydrogen in which the hydrogen is $\frac{1}{8}$ th to $\frac{1}{14} \mathrm{th}$, or from eight to twelve per cent., fire imperfectly, and leave oxygen, hydrogen, and azote.

Common air and hydrogen in which the hydrogen is $\frac{1}{15}$ th or less than seven per cent, do not explode.

It should be observed that when one of the gases is so far deficient as not to allow of an explosion by a single spark, the effect may be obtained by a current of sparks for a longer or shorter period, accompanied by the requisite diminution of volume. In such instances where the effect is produced only by a current of sparks it may be proper here to suggest the reason. When mixtures explode perfectly but feebly, we see the flame, lighted by the spark, to run down the eudiometer till it reaches the water; when they explode still more feebly, the flame runs perhaps half-way down the tube and is extinguished before it reaches the water. There scarcely can be a doubt that the extinction must be occasioned by the cooling effect of the eudiometer and of the intermixture of the mass of air which has to be heated by the feeble flame. Another Phil. Mag. S. 3. Vol. 12. No.73. Feb. 1838. X 
spark in its passage will re-alight the flame, to suffer a quicker extinction, and so on till at length the combustion is complete. This reason will also explain the excessively slow combustion of azote by the electric spark, as ascertained by Mr. Cavendish, and as I have found by repeated experience. Query, might not this experiment succeed better by heating the eudiometer?

From what we have stated it must be obvious that in order to secure the complete abstraction of either oxygen or hydrogen from mixtures by Volta's eudiometer, we should avoid too near an approach to the limitations we have pointed out; or if that cannot be, we should carefully examine the residue for both gases. The best test for very small portions of oxygen is undoubtedly nitrous gas ; for somewhat larger portions of oxygen or hydrogen, additions of those gases might be made so as to bring the mixtures into proportions capable of being exploded.

\section{Second Method, by Nitrous Gas.}

The nitrous gas eudiometer is of singular utility on many occasions. No other can exceed it in accuracy when mixtures contain very little, as one or two per cent. of oxygen; or on the other hand when nearly the whole of the gas is oxygen. But when the mixture of gases contains from twenty to eighty per cent. of oxygen, as in the case of common air, it is not the best when great exactness is required. The reason is well known; when oxygen and nitrous gas combine, the combination is not like that of oxygen and hydrogen, in uniform proportion. We may take one third of the diminution for oxygen, when mixed over water; but this can be considered only as a first approximation. One hundred parts of oxygen may combine with 130 or 360 parts, or any intermediate quantity of nitrous gas, according to circumstances. When only 1 or 2 per cent. of oxygen are expected I put in 5 or 10 per cent. of nitrous gas, and take one third of the diminution for oxygen. When the oxygen (freed from carbonic acid) is judged to be 90 or more per cent. pure, I put 100 parts of nitrous gas of known purity (say $98 \pm$ ) to 100 of the oxygen, and mark the diminution; I next put in 40 nitrous and mark the diminution, and so on, till there is manifestly a slight portion of nitrous left; then this is to be removed by a small portion of oxygen; finally, knowing the quantity of azote which was in the nitrous gas, the rest must have been introduced by the oxygen.

In this way I find a perfect agreement, whether the nitrous test or the hydrogen is used; but with common air the residue 
is so enlarged with azote as to render the measuring of it not so accurate.

\section{Third Method, by Quadrisulphuret of Lime.}

Quadrisulphuret of lime is an excellent test for oxygen, and may be applied to common air or to other mixtures of which oxygen is a part, up to the purest oxygen. As this and other similar compounds seem to me destined to act an important part in chemical operations, it may not be improper here to give some account of their origin and their constitution, as far as actual experiments have demonstrated.

The alkalies and the alkaline earths that are soluble in water have been long known to combine with sulphur, both in the dry and humid way. In the last century they went by the name of hepar sulphuris, or liver of sulphur, from their colour.

Scheele was the first to use the quadrisulphuret of lime to abstract oxygen from atmospheric air. Lavoisier also made use of the same article; but it was to De Marti of Spain we owe the most successful attempt with the quadrisulphuret of lime to abstract the oxygen from atmospheric air. His memoir, printed in 1795, and reprinted in the Journal de Physique, vol. lii. 1801, may still be read with interest*. All the hepars, when dissolved in water, have usually gone by the harsh name of hydroguretted sulphurets in our English works of chemistry since the commencement of the present century.

In 1798 Berthollet published an essay on the nature and combinations of sulphuretted hydrogen, with reference to the part it acts in the sulphurets. Proust afterwards controverted some of Berthollet's opinions in the 59h volume of the Journal de Physique, 1804. Gay-Lussac, in the 78th volume of the Annales de Chimie, 1811, gives some important results on the mutual action of metallic oxides and alkaline hydrosulphurets; he finds amongst other results that no sulphates are formed, that water is formed, that sulphites or sulphuretted sulphites, and often metallic sulphurets are formed; and that consequently it is not possible to obtain the simple metallic bases of hydrosulphurets by means of hydrosulphurets of their oxides; and that when a sulphuret is dissolved in water, no sulphate is ever formed, as is commonly imagined, but sulphites and sulphuretted sulphites. Some proofs are afterwards given + . Vauquelin, in the 6 th volume of the Annales de Chimie et de Physique, 1817, presents us with a laboured

[* A translation of De Marti's Memoir appeared in Phil. Mag., frist series, vol. ix. p. 250.-EDrT.]

+ See also vol. lxxxv. p. 199 . 


\section{Dr. Dalton on the Constitution of the Atmosphere,}

series of experiments on the alkaline sulphurets, the chief object of which is to ascertain the state of the alkali in the sulphuret, whether it is that of a metal or of an oxide. After many experiments on the sulphurets of potash, soda, and lime in the dry way, and one on sulphuret of lime in the humid way, the anthor sums up, and notwithstanding his leaning to the opinion that the alkalies exist in sulphurets in the state of metals, he is obliged at last to acknowledge " that it is probable, but not yet demonstrated, that in all the sulphurets formed by means of the alkaline oxides by $\mathfrak{a}$ red heat, these last lose their oxygen, and are united to sulphur in the metallic state as is the case with the other metals." Gay-Lussac, in the sequel of the same volume, page 322, in a memoir, animadverts on the before-cited paragraph; and allowing that sulphuric acid is formed when a sulphuret of potash made by a red heat is dissolved in water, he contends, according to a suggestion of Berthollet, that the acid is formed in the instant of solution from the reciprocal action of the sulphuret and the water, rather than from the oxygen of the potash and sulphur. This opinion is countenanced by several combinations of a similar nature, which he has adduced, and which are worth the attention of chemists.

Without adverting at present to my own experiments, I may observe that Sir John Herschel, in an essay in the first volume of the Edinburgh Philosophical Journal, 1819, was the first writer who published an atomic view of the class of salts called sulphuretted sulphites, or hyposulphites, that accorded with what I had long entertained and demonstrated by reiterated and decisive experiments*. In the above-mentioned essay he showed clearly that the hyposulphurous acid is composed of two atoms of sulphur and two of oxygen, which united to one atom of base, as potash or lime, compose an atom of hyposulphite. The formation of those of lime, potash, soda, barytes, and some metallic oxides is more particnlarly explained. A saturated solution of hyposulphite of lime at $50^{\circ}$ he found to be $1 \cdot 30$ specific gravity $\dagger$.

In the 14th volume of the Annales de Chimie et de Physique, Gay-Lussac has given the principal results of Herschel's essays on the hyposulphurous acid with some judicious remarks, but he leaves the subject as one requiring further investigation.

* See New System of Chemical Philosophy, vol. ii. Preface, and p. 105.

+ Dr. Thomson, in a paper on the compounds of chromium in the Transactions of the Royal Society for 1826, disputes the accuracy of this constitution of hyposulphurous acid. I have never had any doubt concerning it since 1815. 
In 1822 Berzelius published a memoir on the alkaline sulphurets. The results of his experiments seemed to him confirmatory of the previous notion of Vauquelin. Those experiments were on the sulphurets of potash and lime made in the dry way; he made only one on lime, which agreed very well with the theory; but this very delicate experiment was not enough to establish so important a law of combination, and I do not find that any one besides has obtained the same result*.

Though I am not prepared to deny that sulphurets of potassium and calcium can be obtained by the process of Berzelius, I am quite satisfied that sulphurets of potash and lime, \&c. may be easily procured in the dry way: of that of lime I have had numberless instances. As the compounds of sulphur and the alkaline earths have been very little subjected to investigation by chemists in general, we find great vacancy in the accounts given of them by the modern compilers of chemical books. For this reason I shall introduce here a few of the results $I$ have obtained in a long series of experiments on this branch of chemical inquiry.

\section{Sulphuret of Lime, in the dry way.}

In 1806 I formed, for the first time, the protosulphuret of lime by heating 50 grains of fallen lime with 50 sulphur in a covered crucible not quite air-tight, so that the escape and combustion of the excess of sulphur might be allowed; when raised to a red heat an addition was made to the weight of the lime; by repeating the dose of the sulphur and heating, a further addition was made to the weight; but repeating the operation a third time seldom made any further addition. 'The weight of the compound was 65 grains; it was a white powder with a tinge of yellow, not caustic, but bitter to the taste.

In 1809 I examined this powder more minutely, and found it was best made by mixing equal weights of pure hydrate of lime and flowers of sulphur, putting the mixture into a covered crucible and heating it slowly to red; when the escape of the sulphur fumes ceases, cool the contents, and again mix them with the same weight of sulphur as in the first operation, and again heat it as above; at last it will be found that 32 parts of hydrate of lime $=24$ lime have combined with 14 of sulphur, or one atom to one + . In the work referred to I have stated that pounded lime and sulphur scarcely form any union by this process, and carbonate of lime and sulphur still less.

* Annals of Philosophy, 1822.

+ See New System of Chemical Philosophy, vol, ii. pages 99 and 102. 
An ingenious pupil of mine, Mr. William Barnett Watson of Bolton, has succeeded in uniting lime and sulphur by heat; instead of taking pounded lime, which has a harsh gritty feel, he takes hydrate of lime, and expels the water by a red heat continued till 32 parts of hydrate are reduced to 24 ; this is a fine soft powder; when 24 parts of this pure and finely di vided lime freed from water are well mixed with 24 parts of sulphur and heated red in a covered crucible, a partial combination takes place, and an increase of weight to the lime; this operation is to be repeated till the additional weight becomes 14 grains, after which no further addition can be effected. Mr. Watson found it require several repetitions. I have since found it may be effected by two or three only. This sulphuret is not used in eudiometry.

\section{Quadrisulphuret of Lime, in the humid way.}

When sulphur and hydrate of lime in almost any proportions are boiled together in water, quadrisulphuret of lime is formed and dissolved in the water; the solution is of a deep yellow colour, and has a very bitter taste. I have not seen in any author the proportion that ought to be used, nor the quantity and specific gravity of the liquid solutions. These are subjects which have engaged my attention. If lime is in excess, the liquid consists of lime-water holding in solution quadrisulphuret of lime. If sulphur is in excess, the liquid consists of water holding in solution quadrisulphuret of lime. I have long known that the œconomical proportions to be used are 32 parts of dry hydrate of lime by weight with 56 of sulphur, that is, one atom of lime with four atoms of sulphur. If more lime than that above be used, it will be found prevalent in the residue; if more sulphur, then the redundant sulphur will be found in the residue. A few ounces of the mixed ingredients may be gently boiled in an iron pan for an hour or more, stirring the liquor occasionally, and covering the pan with a lid to prevent the too free admission of atmospheric air. Or, in order to prevent the action of oxygen on the liquid, a flask may be substituted for the pan; the materials may be put into the flask nearly filled with water, and the flask loosely corked may be immersed in a pan of boiling water so as to be almost covered by the water. The liquor to be preserved should be kept in green glass bottles nearly full, and having ground stoppers. After the boiled liquor has cooled and the sediment subsided, the clear liquor may be decanted, if it be strong or deep coloured the sediment may be washed with a little water, and another quantity of the liquor obtained 
of inferior strength. The sediment may be dried if necessary, and subjected to analysis, as I have mostly done. The quantity and specific gravity of the clear liquors should then be ascertained.

The first quadrisulphuret of lime I made was in 1804; it was very weak, since it only absorbed one fourth of its bulk of oxygen gas; the next that was made took its bulk of oxygen. The next, made in 1806, took $2 \frac{1}{2}$ times its bulk of oxygen. In these no account was taken of quantities or residues of lime and sulphur. After this I saw the necessity of investigating, (1.) the quantities of lime and sulphur mixed; (2.) the quantity and specific gravity of the liquid obtained; and (3.) the quantity and proportion of the materials left in the residue, in order that the rationale of the changes effected might be explained. From 1806 to the present time (1837) I have made no quadrisulphuret of lime without attending to all those particulars. In this period I have made it 23 times, six of which were in flasks, and the rest in iron pans covered as mentioned above; the difference of the two methods I found to be very little: it consisted chiefly in traces of sulphuret of iron being found in the residues when pans were used.

A few trials of the various liquids obtained soon furnished me with a formula for ascertaining the quantities of sulphur and lime in a liquid of given specific gravity; namely, multiply the three leading decimals in the specific gravity of the liquid by 13 , and the product will give the aggregate weight in grains of sulphur and lime in 1000 water grain measures. of the liquid; of this aggregate $\frac{9}{13}$ th will be sulphur, and $\frac{4}{15}$ th lime.

With regard to the residue after boiling and its analysis, it is obvious the residue must consist chiefly of sulphur and lime, which for want of due continuance of the ebullition have escaped combination; and there may be some impurities in the sulphur, or the hydrate of lime may not be free from carbonate, \&c.; but when the residue is comparatively small no material disturbance of proportions in the quadrisulphuret can take place. If the residue be chiefly sulphur, its quantity may be approximated by ignition; but if lime is in excess, it may be estimated by the quantity of muriatic acid required to saturate it.

The following table exhibits a selection of the principal varieties in the proportions of ingredients and products obtained so as to illustrate the foregoing statements. 
$168 \mathrm{Mr}$. Lubbock on the Divergence of the numerical Cocficients

Table of Proportions in Quadrisulphuret of Lime.

\begin{tabular}{|c|c|c|c|c|c|}
\hline & $\begin{array}{l}\text { Quantities of hy- } \\
\text { drate of lime and } \\
\text { sulphur mixed. }\end{array}$ & $\begin{array}{c}\text { Proportions } \\
\text { of lime and } \\
\text { sulphur. }\end{array}$ & $\begin{array}{c}\text { Quantity of liquor obtained } \\
\text { in water grain measures, } \\
\text { and quantities of lime and } \\
\text { sulphur in it. }\end{array}$ & \begin{tabular}{|} 
Measures \\
of oxygen \\
required to \\
saturate \\
l00 liquid.
\end{tabular} & $\begin{array}{l}\text { Quantity of residuc } \\
\text { when dricd. }\end{array}$ \\
\hline 1 & $\begin{array}{l}\text { Hydrate. } \\
120=90 \text { lime } \\
+210 \text { sulphur. }\end{array}$ & $\begin{array}{l}\text { Lime. Sulph } \\
4: 9 \frac{\mathrm{P}}{3}\end{array}$ & $\begin{array}{l}3100 \text { of } 1.056 \text { containing } \\
70 \text { lime }+156 \text { sulph. }\end{array}$ & 900 & $\begin{array}{c}56=16 \text { lime } \\
+40 \text { sulph. }\end{array}$ \\
\hline 2 & $\begin{array}{r}50=37 \text { lime } \\
+50^{*} \text { sulphur. }\end{array}$ & $4: 5 \frac{1}{3}$ & $\mid \begin{array}{c}2200 \text { of } 1 \cdot 0240 \text { contain }^{8} \\
21 \text { lime }+47 \text { sulph. }\end{array}$ & 400 & $\begin{array}{l}20=12 \text { lime } \\
+4 \text { sulph. }+ \text { loss }\end{array}$ \\
\hline 3 & $\begin{array}{r}150=112 \frac{1}{2} \text { lime } \\
+200 \text { sulphur. }\end{array}$ & $4: 7+$ & $\begin{array}{l}1450 \text { of } 1 \cdot 146 \text { containing } \\
85 \text { lime }+190 \text { sulph. }\end{array}$ & 2350 & $\begin{array}{r}+20=7 \text { lime } \\
+13 \text { sulph. }\end{array}$ \\
\hline 4 & $\begin{array}{l}96=72 \text { lime } \\
+168 \text { sulph. } \neq\end{array}$ & $4: 9 \frac{\pi}{3}$ & $\begin{array}{r}2800 \text { of } 1 \cdot 056 \text { containing } \\
63 \text { lime }+141 \text { sulph. }\end{array}$ & $900 \S$ & $\begin{array}{l}34=9 \text { lime } \\
+25 \text { sulph. }\end{array}$ \\
\hline 5 & $\begin{array}{l}35=26 \text { lime } \\
+140 \text { sulph. }\end{array}$ & $4: 21 \cdot 6$ & $\begin{array}{r}1600 \text { of } 1 \cdot 037 \text { containing } \\
23 \cdot 7 \text { lime }+53 \cdot 3 \text { sulph. }\end{array}$ & $600 \$$ & 83 all sulph. \\
\hline
\end{tabular}

[To be continued.]

XXV. On the Divergence of the numerical Coefficients of certain Inequalities of Longitude in the Lunar Theory. By J. W. Luвbоcк, Esq., F.R.S.\|

THE divergence of the numerical coefficients in the lunar 1 theory, made manifest by M. Plana's development of the expressions according to powers of $m$, presents a difficulty in a complete numerical solution of the problem, that is, a solution intended to embrace all quantities which are sensible in practically ascertaining the moon's place with the accuracy required for comparison with the best observations. But the following questions naturally occur: Is there any method of approximation which will serve to select the more considerable terms, rejecting others? Is the divergence due chiefly to the development and expansion, according to powers of $m$, of the divisors introduced by integration? In the latter case the difficulty might be easily avoided; but I fear that each of these questions must be answered in the negative.

In order to illustrate this point I have selected indifferently two terms in the longitude amongst those in which this divergence is met with, and I propose to examine their construction without introducing details which do not bear immediately upon the point referred to.

* Boiled in a flask loosely corked.

+ Lost some of the ingredients by boiling over; hence a deficiency.

$\ddagger$ Boiled in a flask with great care.

\$ The oxygen was determined by especial care in these two cases.

if Communicated by the Author. 